\title{
QUESTÃO DO ZUMBIDO NA ATENÇÃO BÁSICA
}

\section{Helenice Yemi Nakamura, Carla Salles Chamouton, Beatriz Silva Telles*}

\section{Resumo}

O Sistema Único de Saúde (SUS) é pautado por princípios como universalidade, integralidade, equidade, descentralização e participação social, incorporado a esse sistema a partir da Política Nacional de Atenção Básica, encontramos uma rede de cuidados primários estabelecidos pelo nível da atenção básica. Dentro dessa perspectiva encontramos um problema, que atinge mais $25 \%$ da população norte-americana e $22 \%$ da população paulistana, o zumbido, que impacta negativamente a qualidade de vida do indivíduo. Por ser preponderante no cuidado especializado, torna-se necessário a articulação de uma rede de cuidados na atenção básica. $O$ estudo teve como objetivo caracterizar o zumbido de usuários de uma unidade básica de saúde de um municipio de grande porte no estado de São Paulo. Foram 64 sujeitos avaliados, onde foram obtidos dados referentes a gênero, idade, tempo que o sujeito tem, se tratou e onde foi tratado o zumbido.

\section{Palavras-chave:}

atenção básica, zumbido, promoção de saúde

\begin{abstract}
$\begin{array}{lll} & \text { Introdução } \\ \mathrm{Na} \text { Constituição Federal promulgada em 1988, } & \text { Feda }\end{array}$ encontramos os fundamentos do sistema de saúde brasileiro. No documento assume-se a saúde "como direito do cidadão e dever do Estado", com a criação de um sistema pautado pelos princípios de universalidade, integralidade, equidade, descentralização e participação social. $^{1}$
\end{abstract}

A regulamentação do Sistema Único de Saúde, se dá a partir da Lei Orgânica da Saúde (Lei 8.080/1990), que regula as ações e serviços de saúde em todo o território nacional e estabelece, entre outras coisas, os princípios, as diretrizes e os objetivos do sistema².

Dessa maneira, o cuidado inicia-se a partir da atenção básica, em que pese a resolutividade de $80 \%$ dos problemas de saúde da população ${ }^{3}$.

Com proposição do Ministério da Saúde a partir de pactuações entre estados e municípios foi elaborado o Pacto pela Saúde (2006), que culminou na Política Nacional de Atenção Básica (PNAB) ${ }^{4,5}$.

A partir da relação de cuidado estabelecida pela atenção básica, encontramos uma questão que compromete a qualidade de vida de muitas pessoas, o zumbido. Estudos apontam que a incidência de zumbido na população norte americana passa de $25 \%{ }^{6}$, na cidade de São Paulo a prevalência do zumbido foi de $22 \%^{7}$ o que faz desse agravo um problema para a saúde pública.

O zumbido pode ser definido como a percepção de um som sem o estímulo acústico externo, o mesmo pode assumir diferentes sentidos e significados na vida do sujeito, desde algo simples e intermitente até algo que prejudique drasticamente a qualidade de vida do indivíduo. Além disso, a abordagem do zumbido é preponderante no cuidado especializado, sendo necessário articular ações de cuidado na atenção básica ${ }^{8}$. Para que isso seja possível temos que ampliar o estudo nessa área $\mathrm{e}$ consequentemente modificar a escassez de literatura sobre o zumbido na atenção básica.

\section{Resultados e Discussão}

Foram 64 sujeitos avaliados, sendo analisado os dados referentes ao gênero, idade, tempo que o sujeito tem o zumbido em meses, se tratou e onde:

\begin{tabular}{|c|c|}
\hline Média de idade & 59,6 \\
\hline $\begin{array}{l}\text { Média do tempo de zumbido (em } \\
\text { meses) }\end{array}$ & 99,4 \\
\hline \multicolumn{2}{|c|}{ Tabela 1 - Caracterização idade e tempo de zumbido } \\
\hline Homens & 38 \\
\hline Mulheres & 26 \\
\hline Total & 64 \\
\hline \multicolumn{2}{|c|}{ Tabela 2 - Caracterização do gênero } \\
\hline Tratado no Centro de Saúde & 5 \\
\hline $\begin{array}{l}\text { Tratado com Profissional } \\
\text { Especialista }\end{array}$ & 13 \\
\hline $\begin{array}{l}\text { Tratado com Profissional } \\
\text { Particular }\end{array}$ & 13 \\
\hline $\begin{array}{l}\text { Total de sujeitos que trataram } \\
\text { o zumbido }\end{array}$ & 31 \\
\hline
\end{tabular}

Tabela 3 - Caracterização do tratamento do zumbido

\section{Conclusões}

É necessário que o estudos sobre o zumbido na atenção básica sejam realizados visto que é um fenômeno predominantemente estudado no cuidado especializado. Possivelmente com mais estudos sendo realizados no contexto da atenção básica, tratamentos poderão ser realizados nesses contexto ajudando os sujeitos que sofrem com o zumbido.

\section{Agradecimentos}

Prefeitura de Campinas, Centro de Saúde São Marcos e $\mathrm{PIBIC/Unicamp}$

\footnotetext{
${ }^{1}$ BRASIL. Constituição. Constituição da República Federativa do Brasil.

Brasília, DF: Senado Federal: Centro Gráfico, 1988.

${ }^{2}$ BRASIL. Ministério da Saúde. Lei No 8.080 , de 19 de setembro de 1990. Dispõe sobre as condições para a promoção, proteção e recuperação da saúde, a organização e o funcionamento dos serviços correspondentes e dá outras providências. Diário Oficial da União; 19 set 1990.

${ }^{3}$ STARFIELD, Bárbara. Atenção primária: equilíbrio entre necessidades de saúde, serviços e tecnologia Brasília: UNESCO: Ministério da Saúde, 2002.

${ }^{4}$ BRASIL. Ministério da Saúde. Portaria No 2.436, de 21 de setembro de 2017. Estabelece a revisão de diretrizes da Política Nacional de Atenção Básica(PNAB), no âmbito do Sistema Único de Saúde (SUS). Brasilia: Ministério da Saúde, 2017

${ }^{5}$ BRASIL. Ministério da Saúde. Secretaria de Atenção à Saúde. Departamento de Atenção Básica. Política Nacional de Atenção Básica / Ministério da Saúde. Secretaria de Atenção à Saúde. Departamento de Atenção Básica. - Brasília: Ministério da Saúde, 2012.

${ }^{6}$ SHARGORODSKY, Josef; CURHAN, Gary C; FARWELL, Wildon R. Prevalence and characteristics of tinnitus among US adults. Am J Med. 2010; 123:711- 8.

${ }^{7}$ OITICICA, Jeanne; MOREIRA, Roseli Saraiva; Tinnitus prevalence in the city of São Paulo. Braz J Otorhinolaryngol. 2015;81:167-76

${ }^{8}$ CHAMOUTON, Carla Salles; NAKAMURA, Helenice Yemi. Zumbido e atenção básica: uma revisão de

literatura. Distúrbios da Comunicação, São Paulo, v. 29, n. 4, p. 720-726, nov. 2017.
} 